\title{
Manifestação de síndrome paraneoplásica em um cão com hemangiossarcoma cutâneo: relato de caso
}

\author{
Expression of syndrome paraneoplastic in a dog with \\ cutaneous hemangiosarcoma: case report
}

\author{
Alricélia da Silva Camboim*, Márcio Eduardo Melo Benvenutti², Ermano Lucena de Oliveira³, \\ Antônio Fernando de Melo Vaz ${ }^{4}$, Rosangela Maria Nunes da Silva ${ }^{4}$ Antônio Flavio Medeiros Dantas ${ }^{4}$ \& \\ Almir Pereira de Souza ${ }^{4}$ \\ 'Médica veterinária, Mestranda. Programa de Pós-graduação em Medicina Veterinária - PPGMV, Universidade Federal de \\ Campina Grande - UFCG, Patos, PB, Brasil \\ 2Médico veterinário, Residente. Laboratório de Patologia Clínica do Hospital Veterinário, Universidade Federal de Campina \\ Grande - UFCG, Patos, PB, Brasil \\ ${ }^{3}$ Graduando. Universidade Federal de Campina Grande - UFCG, Patos, PB, Brasil \\ ${ }^{4}$ Médica veterinária, DSc. Unidade Acadêmica de Medicina Veterinária, Universidade Federal de Campina Grande - UFCG. \\ Patos, PB, Brasil
}

\section{Resumo}

Objetivou-se com este trabalho relatar um caso de hemangiossarcoma cutâneo em um cão, ressaltando-se os aspectos clínico-patológicos e as alterações paraneoplásicas associadas a esta neoplasia. No exame físico observou-se uma formação nodular irregular de 2,5 cm × 2,0 cm, firme elástico, vermelho escuro, aderido, ulcerado, na face lateral direita do prepúcio. Foi realizado hemograma, dosagens séricas de ureia, creatinina, alanina aminotransferase (ALT), aspartato aminotransferase (AST), fosfatase alcalina (FA), gama glutamil transferase (GGT), glicose, proteínas totais (PT), albumina, globulina, proteína C reativa, $\mathrm{Ca}^{+}, \mathrm{Na}^{+}, \mathrm{K}^{+}, \mathrm{Cl}$ e e P. Realizou-se também avaliação dos parâmetros clínicos frequências cardíaca e respiratória, temperatura corporal e aferição da pressão arterial, citologia da massa tumoral, radiografia torácica, ultrassonografia abdominal e eletrocardiograma. No hemograma as alterações observadas foram eosinofilia e linfopenia, os exames séricos apresentaram-se dentro dos padrões de referência para a espécie. Não foram observadas presença de metástases nos exames de imagem, bem como nenhuma alteração no exame eletrocardiográfico. O animal foi submetido à cirurgia para exérese da neoplasia e realizado exame histopatológico, sendo confirmado o diagnóstico de hemangiossarcoma cutâneo. Concluiu-se que deve-se incluir a eosinofilia e linfopenia como manifestações paraneoplásicas em animais com hemangiossarcoma cutâneo.

Palavras-chave: neoplasia, hemograma, pele, biopsia, citologia, canino.

\begin{abstract}
Our objective in this work was to report a case of cutaneous hemangiosarcoma in a dog, emphasizing the clinical and pathological aspects and paraneoplastic changes associated with this neoplasia. On physical examination, there was an irregular nodule of $2.5 \mathrm{~cm} \times 2.0 \mathrm{~cm}$, elastic firm, dark red, stuck, ulcerated, right on the side of the prepuce. Blood count was conducted, serum levels of urea, creatinine, alanine aminotransferase (ALT), aspartate aminotransferase (AST), alkaline phosphatase (ALP), gamma-glutamyl transferase (GGT), glucose, total protein (TP), albumin, globulin, $\mathrm{C}$ reactive protein, $\mathrm{Ca}^{+}, \mathrm{Na}^{+}, \mathrm{K}^{+}, \mathrm{Cl}$ and $\mathrm{P}$. We also did evaluation of clinical parameters heart rate, respiratory rate, body temperature and measurement of arterial blood pressure. Other tests performed included cytology of the tumor mass, chest x-ray, abdominal ultrasound, and electrocardiogram. Blood count changes observed were eosinophilia and lymphopenia, serum tests were within the reference standards for the species, there were no metastases on imaging studies as well there were no electrocardiographic changes. The animal underwent surgery for resection of the tumor and performed a histological examination, which confirmed the diagnosis of cutaneous hemangiosarcoma. We could conclude that one should include eosinophilia and lymphopenia as paraneoplastic manifestations in animals with cutaneous hemangiosarcoma.
\end{abstract}

Keywords: neoplasia, blood count, skin, biopsy, cytology, canine. \section{BJ M Brazilian Journal of Veterinary Medicine \\ p-ISSN 0100-2430 e-ISSN 2527-2179

Como citar: Camboim, A. S., Benvenutti, M. E. M. Oliveira, E. L., Vaz, A. F. M., Silva, R. M. N., Dantas, A. F. M., \& Souza, A. P. (2017). Manifestação de síndrome paraneoplásica em um cão com hemangiossarcoma cutâneo: relato de caso. Brazilian Journal of Veterinary Medicine, 39(2), 126-132. doi: 10.29374/2527-2179.bjvm025016

Fonte de financiamento: Nenhuma.

Conflito de interesses: Os autores declaram não haver conflito de interesses que precisam ser informados.

Recebido: Dezembro 03, 2015.

Aceito: Junho 15, 2016.

O estudo foi realizado na Universidade Federal de Campina Grande - UFCG, Patos, PB, Brasil.

\section{*Correspondência}

Alricélia da Silva Camboim

Programa de Pós-graduação em Medicina Veterinária - PPGMV, Universidade Federal de Campina Grande - UFCG

Avenida Universitária, s/n, Bairro Santa Cecília CEP 58708-110 - Patos (PB), Brasil

E-mail: alriceliamv@gmail.com
Copyright Camboim et al. Este é um artigo publicado em acesso aberto (Open Access) sob a licença Creative Commons Attribution Non-Commercial, que permite uso, distribuição e reproduçãa em qualquer meio, sem restrições desde que sem fins comerciais e que o trabalho original seja corretamente citado. 


\section{Introdução}

O hemangiossarcoma (HSA) éuma neoplasia maligna, que se origina das células endoteliais dos vasos, portanto, pode se originar em qualquer tecido vascularizado (Hammer, 2004; Fernandes \& De Nardi, 2008). Todavia, as maiores incidências primárias são em baço, átrio direito, tecido subcutâneo e fígado (Schultheiss, 2004).

O HSA, quando cutâneo, localiza-se na derme podendo estender-se para o subcutâneo, com uma predileção pela pele abdominal ventral, prepucial e os membros pélvicos (Page \& Thrall, 2004; Fernandes \& De Nardi, 2008; Ferraz et al., 2008; Gabor \& Vanderstichel, 2009). Sugere-se que animais com pele menos pigmentada ou com pelos mais rarefeitos e exposição excessiva à luz ultravioleta são mais predispostos ao seu surgimento (Ferraz et al., 2008; Fernandes \& De Nardi, 2008). As raças susceptíveis são o Pastor Alemão, Beagle, Bulldog, Pointer Inglês, Golden Retriever, Labrador, Boxer, Pitbull e Dalmatas (Mukaratirwa et al., 2005). Segundo Souza et al. (2006) e Fosmire et al. (2004) os cães machos são mais acometidos, ao passo que Fernandes \& De Nardi (2008) afirmam não haver predisposição sexual. Afetam geralmente cães com idade entre 4 e 14 anos (Morz \& Schweigert, 2007; Ferraz et al., 2008).

A sintomatologia clínica apresentada pode variar de acordo com a presença ou não de metástases e dos sinais clínicos decorrentes da presença de síndromes paraneoplásicas como coagulação intravascular disseminada (CID) e anemia, sendo comum a presença de hemorragias espontâneas (Bergman, 2000; Hammer, 2004; Schultheiss, 2004; Marcasso et al., 2010).

As síndromes paraneoplásicas descritas em animais com HSA incluem anemia, trombocitopenia, coagulação intravascular disseminada (CID), leucocitose neutrofílica, hipoglicemia, febre e polineuropatia (Gaschen \& Teske, 2004; Ogilvie, 2004; Mangieri, 2008). Écomumente observado anemia hemolítica microangiopática, devido a presença de fibrina no leito intravascular decorrente da CID (Lucas \& Rodrigues, 2015). Pode-se observar também leucocitose neutrofílica, que pressupõe-se ser decorrente da liberação autônoma pelas células neoplásicas de citocinas ou fatores de crescimento hematopoiético (Ogilvie, 2004).

Os dados relacionados as síndromes paraneoplásicas em animais com HSA são restritos, sendo necessário mais pesquisas com intuito de identificar a ocorrência de tais alterações. Desta forma, objetivou-se com este estudo relatar um caso de hemangiossarcoma cutâneo em um cão atendido no Hospital Veterinário (HV) da Universidade Federal de Campina Grande (UFCG) em Patos-PB, ressaltando-se os aspectos clínico-patológicos e alterações paraneoplásicas, associadas a esta neoplasia.

\section{Histórico}

Foi atendido no setor de Clínica Médica de Pequenos Animais, do Hospital Veterinário da Universidade Federal de Campina Grande, Patos-PB, um cão, macho, sem raça definida, com 8 anos de idade, pesando 19,750 Kg, com histórico de aumento de volume avermelhado, no prepúcio, com sangramento esporádico, observado há mais ou menos dois meses. Alimentava-se de comida caseira e ração de gato. Não era vermifugado, e vacinado apenas com a vacina antirábica e apresentava normodipsia enormofagia. O paciente foi submetido ao exame físico e apresentava-se em bom estado geral, mucosas coradas, hidratado, frequência cardíaca de 80 batimentos por minuto, frequência respiratória de 48 movimentos por minuto, temperatura corpórea de $39,4^{\circ} \mathrm{Ce}$ linfonodos vísiveis sem alteração. Observou-se uma formação nodular irregular de 2,5 cm × 2,0 cm, de consistência firme elástico, coloração vermelho escuro, aderido, com superfície rugosa eulcerado, localizado caudalmente na face lateral direita do prepúcio (Figura 1). Aferiu-se a pressão arterial sanguínea através do método oscilométrico, realizando-se 5 mensurações repetidas e obtendo-se a média destes valores e foi coletada amostra de sangue da veia cefálica para a realização de hemograma, dosagem sérica de alanina aminotransferase, aspartato aminotransferase, fosfatase alcalina, gama glutamil transferase, proteínas totais, albumina, globulina, glicose, ureia, creatinina, cálcio, fósforo, sódio, potássio, cloro e proteína C reativa (PCR). O animal foi submetido à avaliação eletrocardiográfica, à radiografia torácica (projeções látero-lateral bilateral e ventro-dorsal) e ultrassonografia abdominal, para a detecção de possíveis metástases. Foi realizada uma punção aspirativa por agulha fina do tumor para realização de exame citológico. 
A média obtida dos valores de pressão arterial mensurados foram $142 \mathrm{mmHg}$ (pressão arterial sistólica), 122,6 mmHg (pressão arterial média) e 109,4 mmHg (pressão arterial diastólica) de 109,4 mmHg.

No hemograma (Tabela 1) as alterações observadas foram eosinofilia e linfopenia. Na avaliação bioquímica e da PCR (Tabela 2) os valores obtidos apresentaram-se dentro dos padrões de referência para a espécie (Kerr, 2007; Martínez-Subiela et al., 2004; Kaneko et al., 2008).

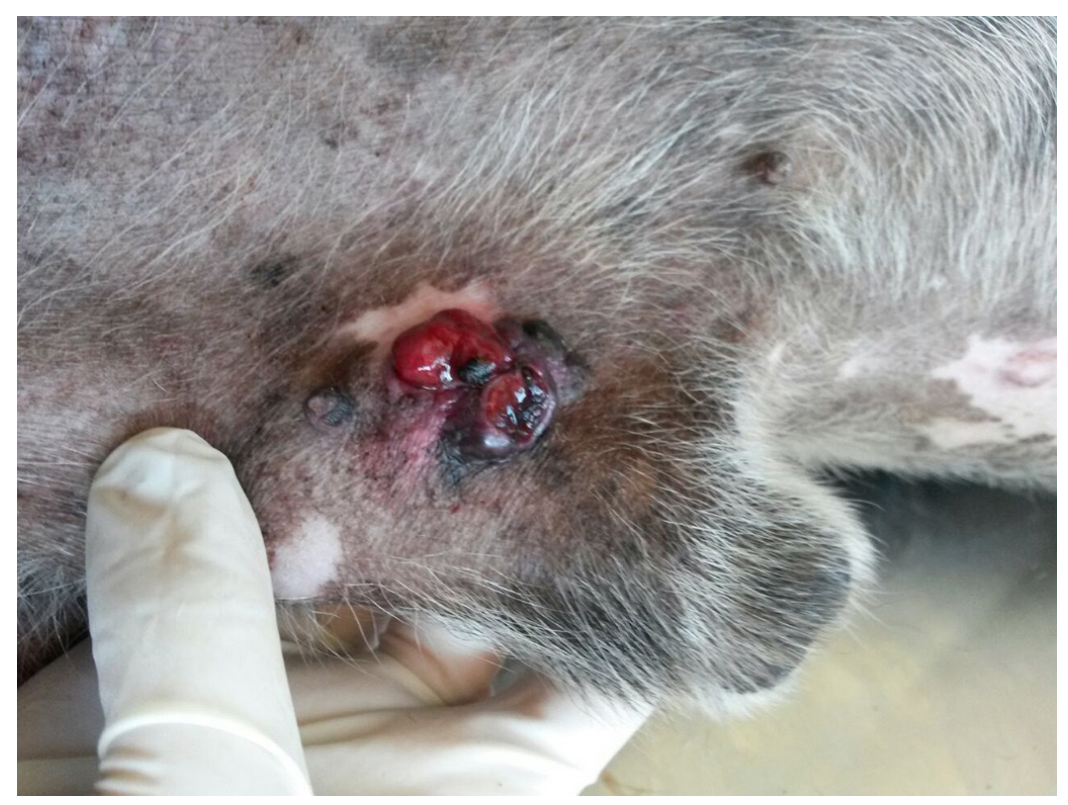

Figura 1. Canino, macho, formação nodular irregular de 2,5 cm × 2,0 cm, consistência firme elástica, coloração vermelho escuro, aderido, superfície rugosa eulcerado, localizado caudalmente na face lateral direita do prepúcio.

Tabela 1. Valores do hemograma de um cão macho, sem raça definida, 8 anos, com hemangiossarcoma cutâneo, atendido no Hospital Veterinário da Universidade Federal de Campina Grande, Patos-PB, realizados antes e 15 dias após a cirurgia para exérese da neoplasia.

\begin{tabular}{cccc}
\hline Parâmetros hematológicos & Pré-cirúrgico & Pós-cirúrgico & $\begin{array}{c}\text { Valores de } \\
\text { referência* }\end{array}$ \\
\hline Hemácias (106/uL) & 7,76 & 8,5 & $5,5-8,5 \times 10^{6} / \mathrm{uL}$ \\
Hematócrito (\%) & 49,0 & 54,0 & $37-55 \%$ \\
Hemoglobina (g/dL) & 16,7 & 18,5 & $12-18 \mathrm{~g} / \mathrm{dL}$ \\
VCM (fl) & 63,1 & 63,5 & $60-77 \mathrm{fl}$ \\
HCM (pg) & 21,5 & 21,8 & $19-23 \mathrm{pg}$ \\
CHCM (g/dL) & 34,1 & 34,3 & $32-36 \mathrm{~g} / \mathrm{dL}$ \\
Leucócitos (103/uL) & 10,8 & 7,9 & $6-17 \times 10^{3} / \mathrm{uL}$ \\
Neutrófilos segmentados (103/uL) & 8,31 & 5,37 & $3-11,5 \times 10^{3} / \mathrm{uL}$ \\
Linfócitos (uL) & 648 & 948 & $1000-4800 / \mathrm{uL}$ \\
Monócitos (uL) & 324 & 158 & $150-1350 / \mathrm{uL}$ \\
Eosinófilos (uL) & 1512 & 1422 & $100-1250 / \mathrm{uL}$ \\
Basófilos (raros) & 0 & 0 & Raros \\
Plaquetas (mm3) & 250 & 190 & $200-500 / \mathrm{mm} 3$ \\
\hline
\end{tabular}

*Weiss \& Wardrop (2010). VCM: Volume corpuscular médio; HCM: Hemoglobina corpuscular média; CHCM: Concentração de hemoglobina corpuscular média. 
A radiografia torácica e a ultrassonografia abdominal não demonstraram presença de metástases, apenas esplenomegalia foi observado na ultrassonografia. O eletrocardiograma não apresentou nenhuma anormalidade. Os achados citológicos indicou um tumor de células mesenquimais, sugestivo de hemangiossarcoma (Figura 2).

Tabela 2. Valores bioquímicos, eletrolíticos e de proteína C reativa de um cão macho, sem raça definida, 8 anos, com hemangiossarcoma cutâneo, atendido no Hospital Veterinário da Universidade Federal de Campina Grande, Patos-PB, realizados antes e 15 dias após a cirurgia para exérese da neoplasia.

\begin{tabular}{cccc}
\hline Variáveis & $\begin{array}{c}\text { Valores } \\
\text { Pré-cirúrgicos }\end{array}$ & $\begin{array}{c}\text { Valores } \\
\text { Pós-cirúrgicos }\end{array}$ & $\begin{array}{c}\text { Valores de } \\
\text { referências }\end{array}$ \\
\hline Alanina aminotransferase (U/L) & 34,1 & 22,4 & $21-102 \mathrm{U} / \mathrm{L}^{*}$ \\
Aspartato aminotransferase (U/L) & 39,0 & 48,9 & $23-66 \mathrm{U} / \mathrm{L}^{*}$ \\
Fosfatase alcalina (U/L) & 37,2 & 41,1 & $20-156 \mathrm{U} / \mathrm{L}^{*}$ \\
Gama glutamil transferase (U/L) & 4,6 & 5,0 & $1,2-6,4 \mathrm{U} / \mathrm{L}^{*}$ \\
Proteínas totais g/Dl & 6,4 & 6,5 & $5,4-7,1 \mathrm{~g} / \mathrm{dL}$ \\
Albumina (g/dL) & 2,88 & 3,94 & $2,6-3,3 \mathrm{~g} / \mathrm{dL}$ \\
Globulina (g/dL) & 3,52 & 2,56 & $2,7-4,4 \mathrm{~g} / \mathrm{dL}$ \\
Glicose (mg/dL) & 94,0 & 96,03 & $65-118 \mathrm{mg} / \mathrm{dL}$ \\
Ureia (mg/dL) & 27,07 & 27,48 & $21,4-59,92 \mathrm{mg} / \mathrm{dL}$ \\
Creatinina (mg/dL) & 0,8 & 0,9 & $0,5-1,5 \mathrm{mg} / \mathrm{dL}$ \\
Potássio (mmol/L) & 4,41 & 4,16 & $3,3-5,5 \mathrm{mmol} / \mathrm{L}^{* *}$ \\
Sódio (mmol/L) & 141,04 & 141,96 & $135-155 \mathrm{mmol} / \mathrm{L}^{* *}$ \\
Cálcio (mg/dL) & 10,79 & 11,69 & $9-11,3 \mathrm{mg} / \mathrm{dL}$ \\
Fósforo (mmol/L) & 2,1 & 2,5 & $1-2,5 \mathrm{mmol} / \mathrm{L}^{* *}$ \\
Cloro (mmol/L) & 113,77 & 115,12 & $100-115 \mathrm{mmol} / \mathrm{L}^{* *}$ \\
Proteína C reativa (mg/dL) & 0,4 & 0,1 & $0,22-4,04 \mathrm{mg} / \mathrm{L}^{* * *}$ \\
\hline
\end{tabular}

*Kerr (2007); **Kaneko et al. (2008); ${ }^{* * *}$ Martínez-Subiela et al. (2004).

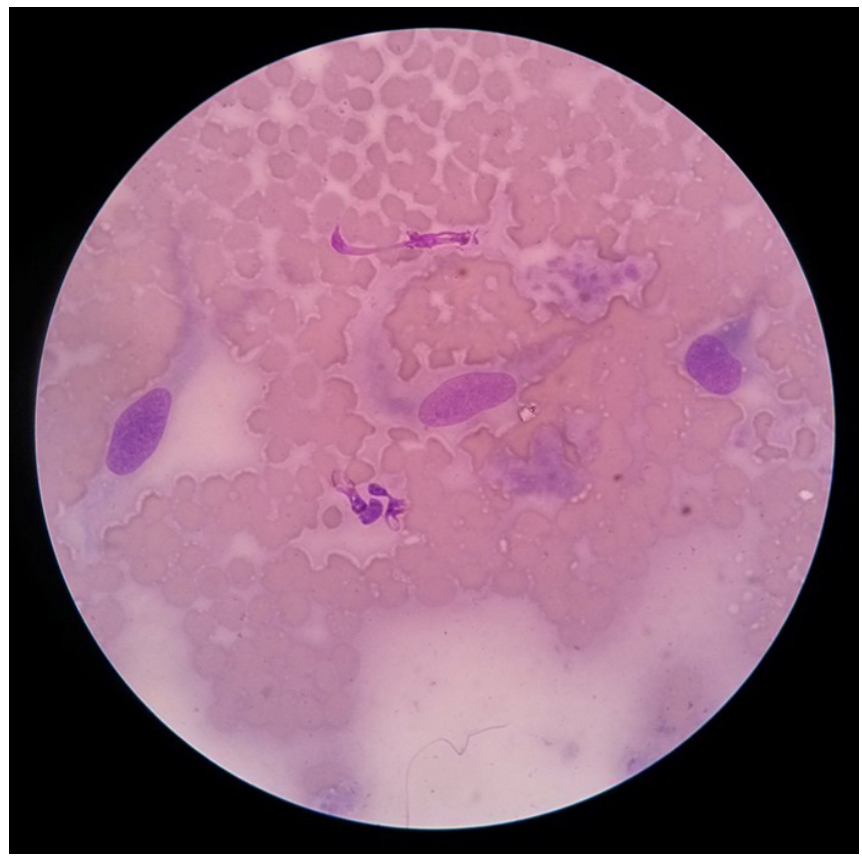

Figura 2. Citologia apresentando baixa celularidade, poucas células individuais ovaladas, núcleo ovalado a discretamente arredondado, com cromatina moderamente grosseira, nucléolos pouco proeminentes e por vezes múltiplos, citoplasma basofílico contendo vacúolos e bordos citoplasmáticos indistintos, imersa em fundo de lâmina contendo inúmeras hemácias. Presença de moderada quantidade de neutrófilos. Panótico. Obj. 100x. 
O animal foi submetido à cirurgia para exérese da neoplasia e coletado material, o qual foi enviado ao Laboratório de Patologia Animal da referida instituição para realização de exame histopatológico, sendo confirmado o diagnóstico de hemangiossarcoma cutâneo.

O paciente retornou ao HV quinze dias após a cirurgia para retirada dos pontos, quando foi reavaliado; não foram observados quaisquer sinais de alteração de recidiva tumoral cutânea. Neste momento repetiu-se os exames eno hemograma (Tabela 1) observou-se uma trombocitopenia discreta; o número de eosinófilos permaneceu acima dos valores de referência, como também os linfócitos permaneceram diminuídos. Observou-se concentrações de albumina discretamente aumentada e diminuição da globulina, com discreta elevação do cálcio. Foi orientado a realização de reavaliações periódicas com intervalos de 90 dias para acompanhamento da evolução do caso.

\section{Discussão}

O HSA cutâneo por si é considerado como de manifestação incomum (Flores et al., 2012; Santos \& Marujo, 2012) sendo a apresentação prepucial como a deste caso mais rara ainda. A ausência de metástases neste caso correlaciona-se com os dados descritos por Fernandes \& De Nardi (2008) que afirmaram que a forma cutânea apresenta baixo potencial metastático. Quanto a causa, a localização na região prepucial contradiz a suposição de que a exposição à luz ultravioleta relaciona-se com o surgimento do HSA (MacWen, 2001), já que a região é menos exposta à incidência da luz solar.

Dentre as alterações hematológicas relatadas em animais com HSA, anemia, trombocitopenia e CID são muito frequentes (Lucas \& Rodrigues, 2015), no entanto, tais alterações não foram observadas neste paciente. Atribui-se que a localização da neoplasia, a extensão tumoral e as manifestações metastáticas influem no desencadeamento destas alterações e que possivelmente ocorram mais comumente em animais com HSA viscerais, formas mais comuns, e que geralmente cursam com um quadro mais grave, apresentando variadas manifestações clínicas de acordo com os órgãos afetados.

Com relação as alterações leucocitárias, a eosinofilia possivelmente decorreu do mecanismo de ação promovido pelas substâncias liberadas pelas células tumorais entre elas TNF- $\alpha$, IL-1, IL-6 e IL-5 que estimulam o aumento na produção de eosinófilos, que também foi observado por Marchetti et al. (2005) Childress (2012) e Duda (2014) em animais com linfoma, mastocitoma e neoplasias mamárias. É importante também considerar que se trata de uma neoplasia cutânea, ou seja, há um processo de injúria tecidual em um tecido rico em mastócitos, os quais são quimiotáticos para eosinófilos, um fator que também pode desencadear o aumento dos eosinófilos (Thrall et al., 2006).

A linfopenia observada, corrobora com os dados descritos por Watabe et al. (2011) que demostraram que em cães com neoplasias há redução do número de linfócitos. Apesar de não ter sido possível identificar a linhagem de linfócitos reduzida (T ou B), pode-se inferir neste caso que a redução do número total de linfócitos possa se dar em decorrência das células T regulatórias que possuem ação inibitória sobre os linfócitos T, causando depleção destes, conforme também relatou Garrido et al. (2015) em animais com neoplasias mamárias.

A ausência de alterações nos exames séricos realizados (Tabela 2), atribui-se a pequena dimensão da neoplasia, a localização cutânea e a ausência de metástases, demonstrando que o animal se encontrava em um bom estado clínico geral, com parâmetros fisiológicos considerados normais para a espécie (Feitosa, 2008).

Com relação a PCR, trabalhos descritos por Calazans et al. (2009), Planellas et al. (2009), Tecles et al. (2009), Crossley et al. (2010), Galezowski et al. (2010), Mukorera et al. (2011) e Battisti et al. (2013) demostraram elevação dos níveis séricos desta, em animais com neoplasias malignas como neoplasia mamária, linfoma, câncer pancreático e carcinoma de células escamosas. Dados estes, que não se correlacionaram com o presente relato, onde não foi verificado o aumento sérico desta proteína, sugerindo-se que as variações séricas da PCR em animais com neoplasias podem ocorrer em função da cronicidade da inflamação tecidual, dimensão do tumor e presença de metástases (Tecles et al., 2009; Crossley et al., 2010). Assim pode-se afirmar que houve um menor processo de antigenicidade neoplásica, não desencadeando variações séricas da PCR.

É importante ressaltar ainda a realização de eletrocardiograma e mensuração da pressão arterial, como exames essenciais para assegurar o não comprometimento da função cardíaca. 
Como também, faz-se necessário a realização de radiografia torácica e ultrassonografia abdominal, para descartar possíveis metástases, um fator importante no prognóstico do paciente (Santos \& Marujo, 2012).

\section{Conclusão}

Neste estudo observou-se a ocorrência de eosinofilia e linfopenia, as quais possivelmente são manifestações paraneoplásicas associadas a esta neoplasia, e devem ser consideradas em pacientes com hemangiossarcoma.

\section{Referências}

Battisti, M. K. B., Silva, D. M., Reusing, M. S. O., Beltrame, O. C., Schmidt, E. M. S., Fagliari, J. J., Dittrich, R. L., \& Guérios, S. D. (2013). Proteínas de fase aguda em cadelas com neoplasia mamária. Ciência Rural, 43, 902-907.

Bergman, P. J. C. (2000). Hemangiosarcoma. In S. J.Ettinger \& E. C. Feldman (Eds.), Textbook of veterinary internal medicine (4th ed., pp. 758-761). Philadelphia: W.B. Saunders Company.

Calazans, S. G., Daleck, C. R., Fagliari, J. J., Repetti, C. F., De Nardi, A. B., Castro, J. H. T., Fernandes, S. C., César, J. R. F., \& Rodigheri, S. M. (2009). Proteinograma sérico de cães sadios e com linfoma obtido por eletroforese em gel de poliacrilamida (SDS-PAGE). Arquivo Brasileiro de Medicina Veterinária e Zootecnia, 61, 1044-1048.

Childress, M. O. (2012). Hematologic abnormalities in the small animal cancer patient. The Veterinary Clinics of North America: Small Animal Practice, 42(1), 123-155. PMid:22285162.

Crossley, R., Coloma, A., Ríos, C., \& González, C. (2010). Determinación de proteína C-reactiva en embras caninas con tumores mamarios benignos y malignos. Archivos de Medicina Veterinaria, 42, 101-105.

Duda, N. C. B. (2014). Anormalidades hematológicas, bioquímicas e hemostáticas de origem paraneoplásica em fêmeas caninas com neoplasia mamária (Dissertação de mestrado). Universidade Federal do Rio Grande do Sul, Porto Alegre. Recuperado em 12 de setembro de 2015, de http://www.lume.ufrgs.br/handle/10183/96929

Feitosa, F. L. F. (2008). Semiologia veterinária: a arte do diagnóstico. São Paulo: Roca. 735 p.

Fernandes, S. C., \& De Nardi, A. B. (2008). Hemangiossarcoma. In C. R. Daleck, A. B. De Nardi \& S. Rodaski (Eds.), Oncologia em cães e gatos (p. 532). São Paulo: Roca.

Ferraz, J. S., Roza, M. R., Caetano Júnior, J., \& Costa, A. C. (2008). hemangiossarcoma canino: revisão de literatura. Jornal Brasileiro de Ciência Animal, 1, 35-48.

Flores, M. M., Panziera, W., Kommers, G. D., Irigoyen, L. F., Barros, C. S. L., \& Fighera, R. A. (2012). Aspectos epidemiológicos e anatomopatológicos do hemagiossarcoma em cães: 40 casos (1965-2012). Pesquisa Veterinária Brasileira, 32, 1319-1328.

Fosmire, S. P., Dickerson, E. B., Scott, A. M., Bianco, S. R., Pettengill, M. J., Meylemans, H., Padilla, M., FrazerAbel, A. A., Akhtar, N., Getzy, D. M., Wojcieszyn, J., Breen, M., Helfand, S. C., \& Modiano, J. F. (2004). Canine malignant hemangiosarcoma as a model of primitive angiogenic endothelium. Laboratory Investigation, 84(5), 562-572. PMid:15064773.

Gabor, L. J., \& Vanderstichel, R. V. (2009). Primary hemangiosarcoma. Veterinary Pathology, 43(5), 782-784. PMid:16966462.

Galezowski, A. M., Snead, E. C. R., Kidney, B. A., \& Jackson, M. L. (2010). C-Reative Protein as a prognostic indicator in dogs with acute abdomen syndrome. Journal of Veterinary Diagnostic Investigation, 22(3), 395401. PMid:20453213.

Garrido, E., Castanheira, T. L. L., Vasconcelos, R. O., Machado, R. Z., \& Alessi, A. C. (2015). Alterações hematológicas em cadelas acometidas por tumores mamários. Pubvet, 9, 291-297.

Gaschen, F. P., \& Teske, E. (2004). Paraneoplastic syndromes. In S. J. Ettinger \& E. C. Feldman (Eds.), Textbook of veterinary internal medicine (6th ed., pp. 789-795). Philadelphia: W.B. Saunders Company.

Hammer, A. (2004). Hemangiossarcoma. In R. C. Rosenthal (Ed.), Segredos em oncologia veterinária (pp. 253260). Porto Alegre: Artmed.

Kaneko, J. J., Harvey, J. W., \& Bruss, M. L. (2008). Clinical biochemistry of domestic animals (6th ed., p. 896). New York: Academic.

Kerr, M. (2007). Exames laboratoriais em medicina veterinária: bioquímica clínica e hematologia (2. ed., p. 582). São Paulo: Roca.

Lucas, S. R. R., \& Rodrigues, L. C. S. (2015). Síndromes paraneoplásicas. In M. M. Jericó, M. M. Kogika \& J. P. Andrade Neto (Eds.), Tratado de medicina interna de cães e gatos (pp. 507-515). Rio de Janeiro: Roca.

MacWen, E. G. (2001). Miscellaneous tumors. In S. J. Withrow \& E. G. Macewen (Eds.), Small animal clinical oncology (pp. 639-646). Philadelphia: W.B. Saunders.

Mangieri, J. (2008). Síndromes paraneoplásicas. In C. R. Daleck, A. B. De Nardi, \& L. Rodaski (Eds.), Oncologia em cães e gatos (pp. 237-252). Rio de Janeiro: Roca.

Marcasso, R. A., Arias, M. V. B., Rodrigues, P. C., \& Bracarence, A. P. F. R. L. (2010). Hemangiossarcoma cutâneo paravertebral em cão causando compressão medular. Semina: Ciências Agrárias, 31, 473-478. 
Marchetti, V., Benetti, C., Citi, S., \& Taccini, V. (2005). Paraneoplastic hypereosinophilia in a dog with intestinal T-cell lymphoma. Veterinary Clinical Pathology, 34(3), 259-263. PMid:16134075.

Martínez-Subiela, S., Ginel, P. J., \& Cerón, J. J. (2004). Effects of different glucocorticoid treatments on serum acute phase proteins in dogs. The Veterinary Record, 154(26), 814-817. PMid:15260442.

Morz, L. R., \& Schweigert, A. (2007). Hemangiossarcoma em cães. Ars Veterinária, 2, 50-55.

Mukaratirwa, S., Chipunza, J., Chitanga, S., Chimonyo, M., \& Bhebhe, E. (2005). Canine cutaneous neoplasms: Prevalence, site distribution and influence of sex and age on the present and malignancy in dogs from Zimbabwe. Journal of the South African Veterinary Association, 76(2), 59-62. PMid:16108522.

Mukorera, V., Dvir, E., Van der Merwe, L. L., \& Goddard, A.L. (2011). Serum C-reactive protein concentration in benign and malignant canine spirocercosis. Journal of Veterinary Internal Medicine, 25(4), 963-966. PMid:21615495.

Ogilvie, G. K. (2004). Síndromes paraneoplásicas. In S. J. Ettinger \& E. C. Feldman (Eds.), Tratado de medicina interna veterinária: doenças do cão e do gato (5. ed, Vol. 1, pp. 529-537). Rio de Janeiro: Guanabara Koogan.

Page, R. L., \& Thrall, D. L. (2004). Sarcomas de Tecidos Moles e Hemangiossarcomas. In S. J. Ettinger \& E. C. Feldman (Eds.), Tratado de medicina interna veterinária: doenças do cão e do gato (5. ed, Vol. 1, pp. 561-566). Rio de Janeiro: Guanabara Koogan.

Planellas, M., Bassols, A., Siracusa, C., Saco, Y., Giménez, M., Pato, R., \& Pastor, J. (2009). Evaluation of serum haptoglobin and C-reactive protein in dogs with mammary tumors. Veterinary Clinical Pathology, 38(3), 348-352. PMid:19392756.

Santos, I. F. C., \& Marujo, R. (2012). Hemangiossarcoma cutâneo canino com metástase esplênica-relato de caso. Medvep, 2(4), 198-202.

Schultheiss, P. C. (2004). A retrospective study of visceral and nonvisceral hemangiossarcoma and hemangiomas in domestic animals. Journal of Veterinary Diagnostic Investigation, 16(6), 522-526. PMid:15586567.

Souza, T. M., Fighera, R. A., Irigoyen, L. F., \& Barros, C. S. L. (2006). Estudo retrospectivo de 761 tumores cutâneos em cães. Ciência Rural, 36, 555-560.

Tecles, F., Caldín, M., Zanella, A., Membiela, F., Tvarijonaviciute, A., Subiela, S. M., \& Cerón, J. J. (2009). Serum acute phase protein concentrations in female dogs with mammary tumors. Journal of Veterinary Diagnostic Investigation, 21(2), 214-219. PMid:19286500.

Thrall, A. M., Baker, D. C., Campbell, T. W., Penicola, D., Fettiman, N. J., Lassen, E. D., Rebar, A., \& Weiser, G. (2006). Hematologia e bioquímica clínica veterinária (p. 688). São Paulo: Roca.

Watabe, A., Fukumoto, S., Komatsu, T., Endo, Y., \& Kadosawa, T. (2011). Alterations of lymphocyte subpopulations in healthy dogs with aging and in dogs with cancer. Veterinary Immunology and Immunopathology, 142(3-4), 189-200. PMid:21680028.

Weiss, D. J., \& Wardrop, K. J. (2010). Schalm's veterinary hematology (6th ed., p. 1232). Iowa: Wiley-Blackwell. 